\title{
Intraocular haemorrhage as a complication of pneumoencephalography
}

\author{
I. F. MOSELEY AND J. B. PILLING ${ }^{1}$ \\ From the Lysholm Radiological Department, National Hospital for Nervous Diseases, \\ Queen Square, London
}

SYNOPSIS The ocular fundi of 20 patients were examined before and after pneumoencephalography. In four of these, fresh venous retinal haemorrhages were seen, and a further patient had developed an exudate. Possible reasons for a rise in retinal venous pressure include bodily inverting the patient, compression of the thorax, the use of positive pressure respiration, and the air injection itself. It may be advisable to take steps to limit the effects of such possible causative factors.

In 1973, Simon and colleagues published an account of several cases of intraocular haemorrhage resulting from air myelography carried out under general anaesthesia. They described three cases of symptomatic haemorrhage occurring in an uncontrolled series of 480 gas myelographies, while in a pilot series of 19 patients examined before and after myelography there were five patients with asymptomatic retinal or preretinal haemorrhages. At the time of the original presentation of this work, the authors were criticised for what appeared to be 'faulty' techniques and, indeed, they pointed out in a footnote that, after certain modifications to the procedure, no further haemorrhagic incidents occurred. It was also claimed that such complications were specific to gas myelography and did not occur with, for example, pneumoencephalography.

Retinal haemorrhage is not a recognised complication of pneumoencephalography (Milkowski, 1969; Clark et al., 1970; Bergeron and Rumbaugh, 1971), although intracranial haemorrhage, usually subdural, is well documented (Bucy, 1942; Robinson, 1957; Khalifeh et al., 1964; Zotti, 1966; Calkins et al., 1967, Seshia, 1971; Mead, 1973); one case only of retinal haemorrhage appears to have been recorded (Hoyt and Beeston, 1966). However, many

1 Present address: Department of Neurology, St. Bartholomew's Hospital, West Smithfield, London E.C.1.

(Accepted 3 December 1975.) neuroradiologists or neuro-ophthalmologists seem to have encountered individual cases. It therefore seemed desirable to examine systematically a series of patients undergoing pneumoencephalography in order to detect subclinical retinal or preretinal haemorrhage, since, if this were occurring, the possibility of a more serious vitreous haemorrhage would always be present (Simon et al., 1973).

\section{METHODS}

Twenty patients undergoing pneumoencephalography under general anaesthesia at the National Hospital for Nervous Diseases, Queen Square, were examined funduscopically before and after the procedure. In the majority of cases, these examinations were within a few hours of the encephalogram, and a short acting mydriatic was employed. Fluorescein angiography was carried out in one case.

\section{RESULTS}

The patients have been divided into three groups:

1. Those in whom fundal examination was normal before and after the encephalogram (10 patients: Table 1).

2. Those in whom pre-encephalogram funduscopy revealed some abnormality which was unaffected by the radiological procedure (five patients: Table 2).

3. Those in whom some intraocular lesion was 
TABLE 1

PATIENTS WITH NORMAL FUNDI BEFORE AND AFTER PNEUMOGRAPHY

\begin{tabular}{lcl}
\hline Patient & $\begin{array}{c}\text { Age } \\
(y r)\end{array}$ & \\
\hline CH & 58 & Cerebral atrophy \\
PS & 58 & Atrophy + infarct \\
AM & 33 & Cerebellar atrophy \\
HP & 60 & Pituitary adenoma \\
MP & 16 & Retrobulbar neuritis \\
AT & 39 & Chiari malformation + ? syringomyelia \\
JB & 14 & ? Vestibular neuronitis \\
AB & 38 & $?$ \\
TD & 39 & $?$ \\
BM & 51 & Normal \\
\hline
\end{tabular}

TABLE 2

PATIENTS WITH ABNORMAL FUNDI, UNCHANGED AFTER PNEUMOGRAPHY

\begin{tabular}{|c|c|c|c|}
\hline Patient & $\begin{array}{c}\text { Age } \\
(y r)\end{array}$ & Diagnosis & Funduscopy \\
\hline $\begin{array}{l}\text { AP } \\
\text { BR } \\
\text { MR } \\
\text { NS } \\
\text { SR }\end{array}$ & $\begin{array}{l}34 \\
65 \\
16 \\
43 \\
31\end{array}$ & $\begin{array}{l}\text { Ischaemic papillitis } \\
\text { Chordoma } \\
\text { Hydrocephalus } \\
\text { Thalamic tumour } \\
\text { Suprasellar tumour }\end{array}$ & $\begin{array}{l}\text { Papilloedema both eyes } \\
\text { Left optic atrophy } \\
\text { Blurred disc margins } \\
\text { Discs pale } \\
\text { Discs pale }\end{array}$ \\
\hline
\end{tabular}

TABLE 3

PATIENTS WITH INTRAOCULAR CHANGES AFTER PNEUMOGRAPHY (PEG)

\begin{tabular}{|c|c|c|c|c|}
\hline Patient & $\begin{array}{l}\text { Age } \\
(y r)\end{array}$ & Diagnosis & Pre-PEG funduscopy & Post-PEG funduscopy \\
\hline GC & 41 & Optic neuritis & $\begin{array}{l}\text { Questionably swollen discs; venous } \\
\text { pulsation normal }\end{array}$ & $\begin{array}{l}\text { Scattered perimacular, blot } \\
\text { haemorrhages, left more than right }\end{array}$ \\
\hline TS & 54 & Cerebral atrophy & $\begin{array}{l}\text { ? Small haemorrhages left disc } \\
\text { margin }\end{array}$ & $\begin{array}{l}\text { Scattered blot haemorrhages both eyes } \\
\text { plus flame on left }\end{array}$ \\
\hline KF & 11 & Communicating hydrocephalus & Bilateral papilloedema & $\begin{array}{l}\text { Florid, pre-retinal perivenous, } \\
\text { haemorrhages both eyes }\end{array}$ \\
\hline WH & 49 & Recurrent meningioma & $\begin{array}{l}\text { Chronic papilloedema; small } \\
\text { haemorrhage on right }\end{array}$ & $\begin{array}{l}\text { Small, fresh, pre-retinal perivenous } \\
\text { haemorrhages both eyes }\end{array}$ \\
\hline LB & 62 & ? Cholesteatoma & Normal & Small linear exudate on right \\
\hline
\end{tabular}
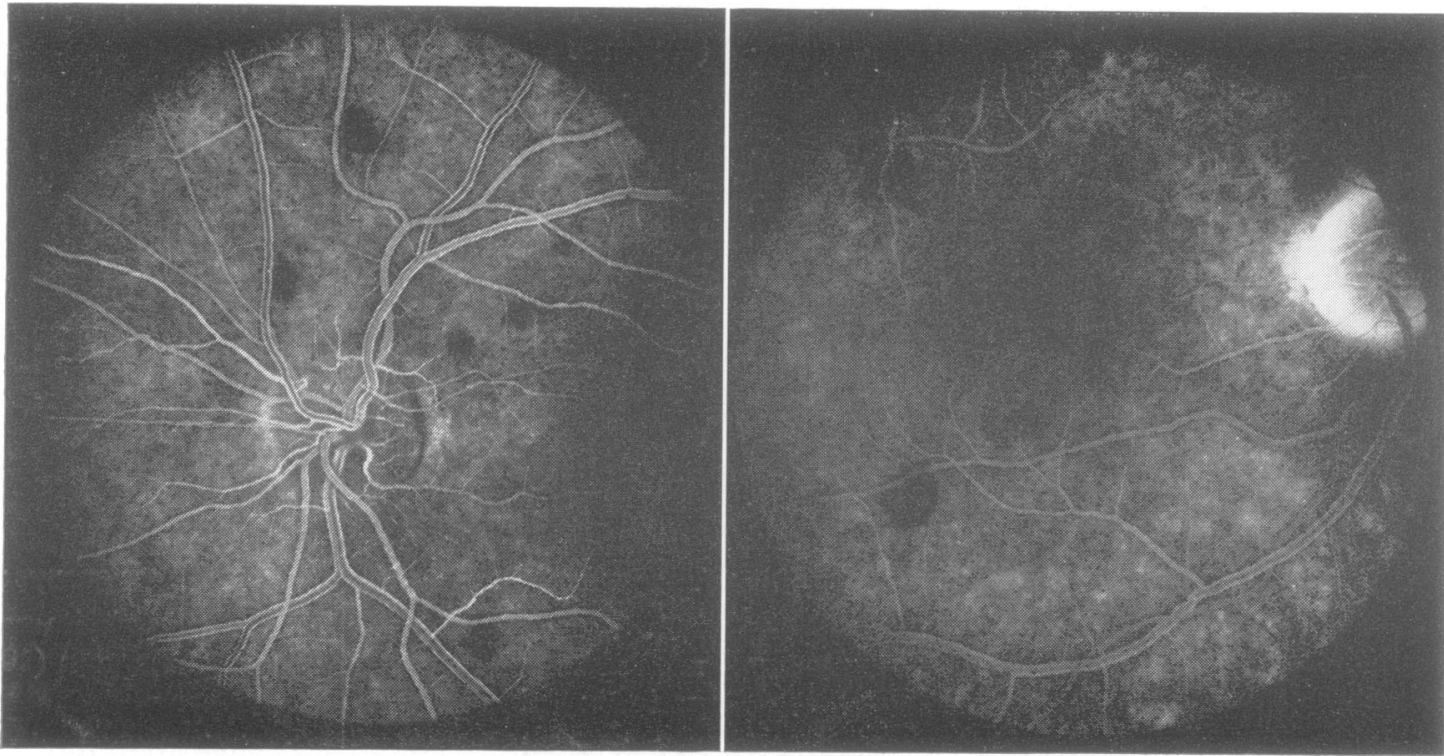

(a)

(b)

FIG.1 Fluorescein angiography, carried out on patient GC, 48 hours after pneumoencephalography (a) left eye, 18 seconds, (b) right eye, five minutes. No significant angiographic abnormality is seen, but small haemorrhages (dark spots) are seen scattered throughout both fundi. 


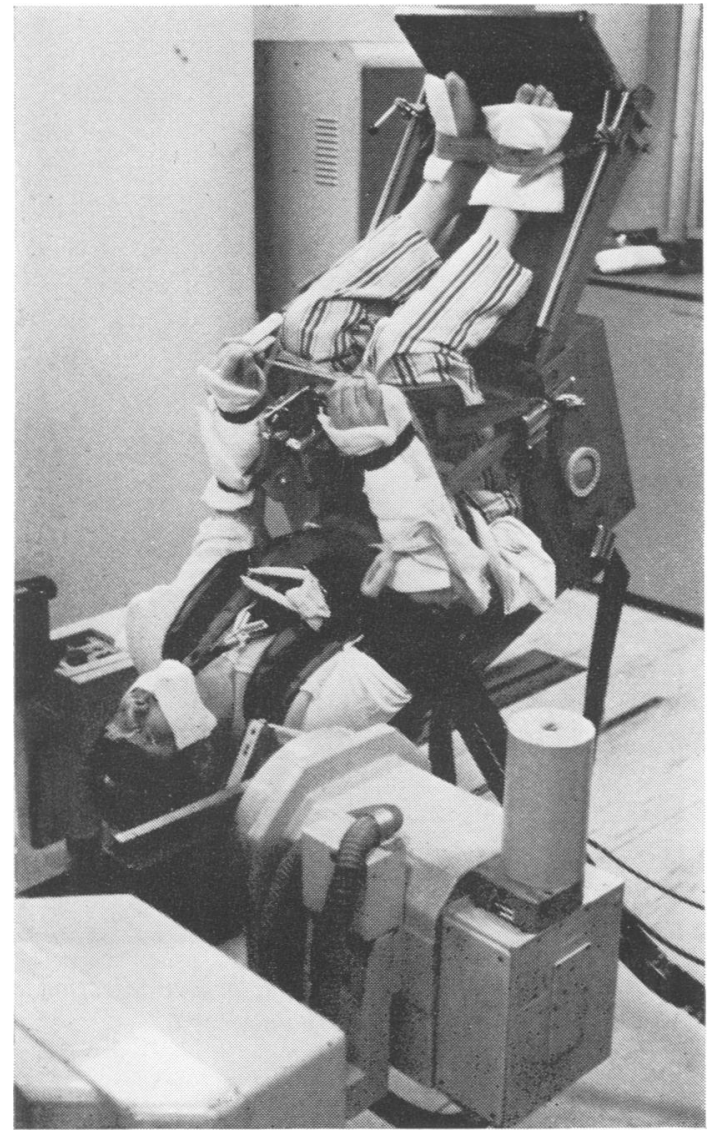

FIG. 2 A patient in the Mimer III chair, in the 'hanging head' position. This may be sustained for several minutes while tomography is carried out. The cuirasse-type harness is shown.

produced or exacerbated by the encephalogram (five patients: Table 3).

In every case, the encephalogram was carried out under general anaesthesia, with atropine premedication, induced with methohexitone and suxamethonium and maintained with a nitrous oxide/oxygen/trichlorethylene mixture and with pancuronium. Intermittent positive pressure respiration was always employed. The patients were placed in the Mimer III apparatus and, in every case, the somersault manoeuvre was used to fill the temporal horns.

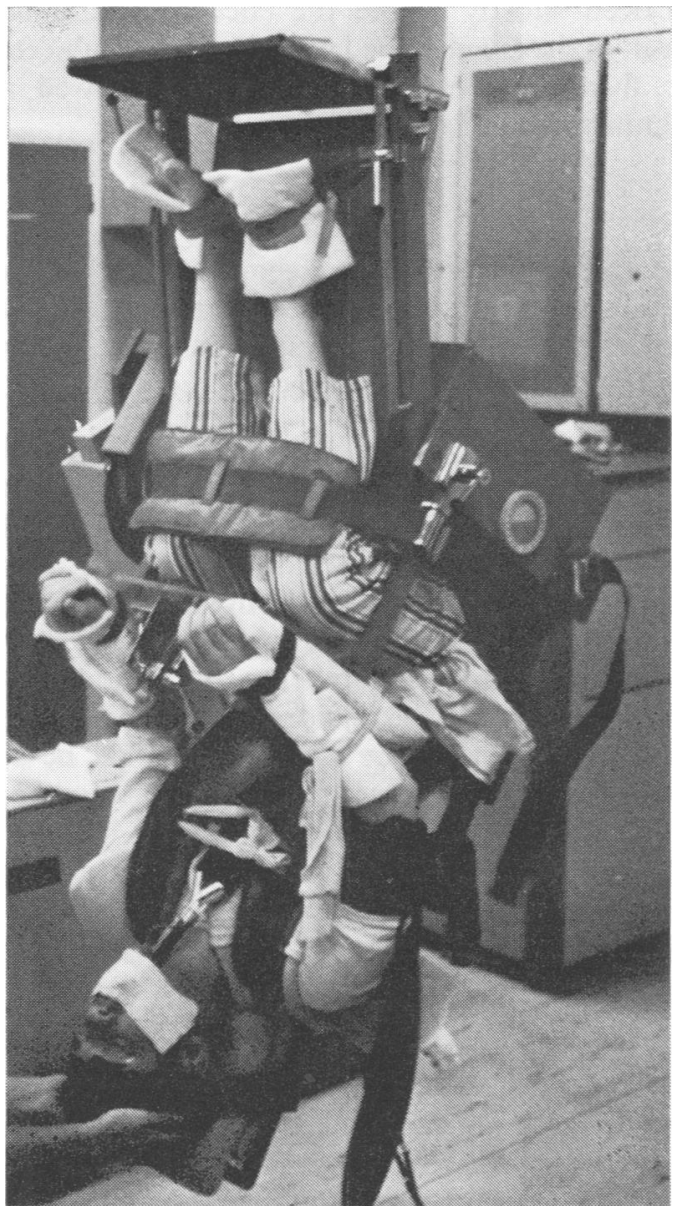

FIG. 3 The patient is inverted during the somersault manoeuvre. The neck veins are engorged, and the facial skin is darker-hued than that of the hands or legs. Much of the weight is taken on the chest.

There was no significant difference between the duration of anaesthesia in groups (1), (2), and (3), the mean for the first two groups being 130 minutes, and for the last 135 minutes. In all three the mean volume of air injected was $35 \mathrm{ml}$.

Of the five patients who showed fresh funduscopic abnormalities after the encephalogram, three denied any visual disturbance as a result of the lesions, while one (WH) still showed a hemianopia which had been present before the procedure. The last (GC) thought that some improvement in his visual acuity which he had 
noticed shortly before the encephalogram had been maintained. This last patient was subjected to fluorescein angiography, which showed no abnormality (Fig. 1).

\section{DISCUSSION}

Since the haemorrhages seem to be of venous origin, factors causing raised intracranial and/or intraocular venous pressure must be sought. In this situation, several may be contributory.

HEAD-DOWN POSITION During much of the procedure, the patient's legs are above the head and in certain positions-for example, when the anterior end of the third ventricle is being examined (Fig. 2) and during the somersault manoeuvre (Fig. 3) - this may be exaggerated. Although no correlation between the duration of anaesthesia and the incidence of haemorrhage was found, this factor cannot, we think, be disregarded. In the case of retinal haemorrhage after an encephalogram described by Hoyt and Beeston (1966), there was a suggestion that an excessive amount of time had elapsed with the patient inverted.

COMPRESSION OF ABDOMEN AND THORAX In the chair of the Mimer III, the anaesthetized patient is supported, in part, by a flexible cuirasse, and much of the weight is taken on this in the 'brow down' position. We have noticed that the neck veins may be engorged and the face rather dusky (Fig. 4) in the erect position, when the pressure on the thorax should be least. Compression injury of the chest is almost certainly the causative factor in Purtscher's disease-traumatic retinal angiopathy-in which retinal exudates and haemorrhages were originally (Purtscher, 1910) thought to be due to an associated head injury. Stockhusen (1938) described traumatic retinal angiopathy in a pilot who crashed while wearing a halter-type safety harness. This was a relatively severe injury, but bilateral retinal haemorrhage occurring after a relatively mild seat-belt injury in a hypertensive man of 66 years was noted by Hoare (1970). It is of interest to note that our patient $\mathrm{AB}$ had developed retinal haemorrhage at the age of 20 years (18 years before the encephalogram) after aerobatics but was unaffected by the radiological procedure. Abnormal fluorescein angiographic findings in

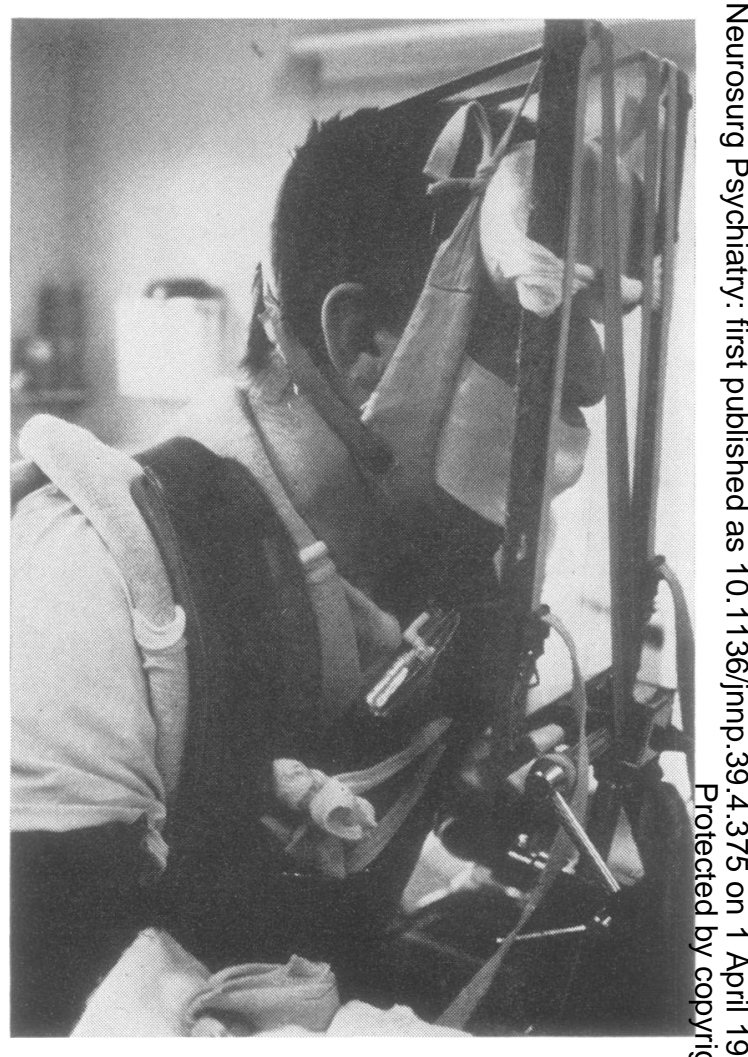

FIG. 4 The initial erect position, before injection of air. The neck veins are clearly engorged.

traumatic asphyxia-a severe form of crush injury in which retinal lesions are found along with severe systemic disturbance-have been reviewed by Ravin and Meyer (1973). The normal findings in the present case are not at variance with this since, clearly, the degree of compression during encephalography is much milder, although, in a discussion of what he termed 'Valsalva haemorrhagic retinopathy', Duane (1973) suggested that frank haemorrhages occurred only with a severe rise in venous pressure, and in a previously diseased retina.

POSITIVE PRESSURE RESPIRATION All the patients in the present study were ventilated with the Manley apparatus, without a significant negative phase. Although the consequent elevation of intrathoracic pressure would be intermittent, it might act in concert with any others to increase 
the intracranial venous pressure. In the small additional series of Simon et al. (1973) carried out after the discovery of the venous haemorrhages (about 10 cases), the respiration did include a negative phase ( -5 to $-10 \mathrm{~cm}$ water $)$; no further haemorrhages were seen. However, other modifications to the techniques had also been introduced. The French authors made no comments on the degree of assistance of ventilation; we routinely hyperventilate the patients, so that the $\mathrm{paCO}_{2}$ is around $30 \mathrm{~cm} \mathrm{Hg}$. This may cause dilatation of the intracranial veins associted with shrinkage of the brain (Moseley and $\mathrm{du}$ Boulay, unpublished observations), but we have no information as to the effects on the intraocular venous pressure.

EFFECTS OF AIR INJECTION It is well known that injection of air at encephalography causes an increase in intracranial pressure, although this may be transient (Cronquist et al., 1963). Finke and Jaenicke (1970), using the technique of ophthalmodynamometry, studied 60 patients undergoing pneumoencephalography carried out in a similar fashion to our studies, but under local anaesthesia. Twenty-four showed an increase of more than $5 \%$ in intraocular pressure as a result of lumbar puncture alone, with a further increase after air was injected. A further six patients showed an elevation of pressure only after air injection. These changes were thought to be due to alterations in ophthalmic arterial pressure, however.

The lack of any apparent correlation between the volume of air injected and the incidence of retinal haemorrhage, in either our series or that of Simon et al. (1973), would suggest that this is not a very important factor, at least quantitatively. A major difference between the two series is that in gas myelography a considerable quantity of cerebrospinal fluid is withdrawn, which is thought to cause intraspinal and possibly intracranial venous dilatation (Masserman, 1935), whereas, in our practice, only a small specimen is taken for analysis.

Of the factors discussed the combination of the first two-compression of the thorax, aggravated by the positions adopted during encephalography-would seem not only to be the most likely to be responsible, but also to be amenable to improvement. Discussions with the manufacturers of the equipment as regards the cuirasse have been initiated and work is projected on assessing the effects of encephalography without the somersault.

Lastly, it must be pointed out that two of the five patients who developed funduscopic abnormalities during encephalography had evidence of raised intracranial pressure. The possibility of intraocular haemorrhage must be added to the known risks of carrying out pneumoencephalography in these patients.

Our thanks are due to $\mathrm{Mr}$ M. D. Sanders for his encouragement and for carrying out the fluorescein angiography; and to the staffs of the Departments of Neuro-ophthalmology and of Medical Illustration of the National Hospital for the preparation of the illustrations.

\section{REFERENCES}

Bergeron, R. T., and Rumbaugh, C. L. (1971). Problems incident to pneumographic and other nonangiographic radiologic contrast studies of the brain. Bulletin of the Los Angeles Neurological Societies, 36, 1-10.

Bucy, P. C. (1942). Subdural haematoma. Illinois Medical Journal, 82, 300-310.

Calkins, R. A., Van Allen, M. W., and Sahs, A. L. (1967). Subdural hematoma following pneumoencephalography. Journal of Neurosurgery, 27, 56-59.

Clark, R. A., Obenchain, T. G., Hanafee, W. N., and Wilson, G. H. (1970). Pneumoencephalography. Comparison of complications in 100 pediatric and 100 adult cases. Radiology, 95, 675-678.

Cronquist, S., Lundberg, N., and Pontin, U. (1963). Cerebral pneumography with continuous control of ventricular fluid pressure. Acta Radiologica, 1, 558-564.

Duane, T. D. (1973). Valsalva hemorrhagic retinopathy. American Journal of Ophthalmology, 75, 637-642.

Finke, V., and Jaenicke, H. (1970). Kreislaufanderungen wahrend Lumbalpunktion und Pneumencephalographie (am Hand ophthalmodynamographischer Befunde). Deutsche Zeitschrift für Nervenheilkunde, 197, 171-180.

Hoare, G. W. (1970). Traumatic retinal angiopathy resulting from chest compression by safety belt. British Journal of Ophthalmology, 54, 667-669.

Hoyt, W. F., and Beeston, D. (1966). The Ocular Fundus in Neurologic Disease. Mosby: St. Louis.

Khalifeh, R. R., Van Allen, M. W., and Sahs, A. L. (1964). Subdural hematoma following pneumoencephalography in an adult. Neurology (Minneap.), 14, 77-80.

Masserman, J. H. (1935). Cerebrospinal hydrodynamics. Studies of the volume and elasticity of the human ventriculo-subarachnoid system. Journal of Comparative Neurology, 61, 543-552.

Mead, S. (1973). Death from acute massive subdural hematoma complicating pneumoencephalography. Bulletin of the Los Angeles Neurological Societies, 38, 166.

Milkowski, S. (1969). Niektore zabiegi diagnostyczne lecznicze jako przyczyna powiklan; objawow uboczych w narzadzie wzroko. Wiadomosei Lekarskie, 22, 1689-1693.

Purtscher, D. (1910). Noch unbekannte Befund nach Schaedeltrauma. Bericht Versammliche Ophthalmologische Gesellschaft, 36, 294-301. 
Ravin, J. G., and Meyer, R. F. (1973). Fluoroscein angiographic findings in a case of traumatic asphyxia. American Journal of Ophthalmology, 75, 643-647.

Robinson, R. G. (1957). Subdural haematoma in an adult after air encephalography. Journal of Neurology, Neurosurgery, and Psychiatry, 20, 131-132.

Seshia, S. S. (1971). Subdural haematoma. Neurology (Bombay), 19, 207-211.
Simon, J., Garrec, A., and Guegan, Y. (1973). Les complications hemorrhagiques oculaires de la myelographie gazeuse. Journal of Radiologie, 54, 675-679.

Stockhusen, P. P. (1938). Über eine seltene Fliegverletzung mit Fern wirkung auf die Augen. Bericht Deutsche Ophthalmologische Gesellschaft, 52, 246-250.

Zotti, G. (1966). Ematoma sottodurale consequente a pneumoencefalografia. Minerva Medica, 57, 2127-2131. 